\title{
A New Trend in Tobacco Use: WHO Report
}

On 19th December 2019,World Health Organization released a news report on global trend of tobacco use. To our utmost surprise, it has reported about decrease in number of male tobacco users in several countries. For several years, the world has witnessed a consistent rise of tobacco use in males, though there was evidence of downward trend of overall global tobacco use due to tremendous fall in female tobacco consumption. But in this new report, WHO Director-General, Dr Tedros Adhanom Ghebreyesus, has informed the declination in tobacco use among males (reduction of more than 1 million users )as a defining moment indicating about the effect of rigorous and strict laws actions taken by the fellow countries. It has also been projected that few countries may achieve $30 \%$ reduction target in tobacco use by 2025. Despite this gain, millions of people including female and children are still using these hazardous tobacco product. Females of middle and low income countries showed continuous fall in tobacco use whereas Europe showed least progress in this regard. In Asia, the southeast Asia region still has the highest rate of tobacco use where China has highest average rate among men.

Though a long way to go, this report indicates the frail but positive results of the efforts of antitobacco movements of both international and national governing bodies. Implementation of strict tobacco control measures including increase in tobacco taxes has not only induced the reduction in tobacco use but also helped in collection of revenues for poor countries. A more stiffer tobacco control policy at national levels targeting the large-scale education programs, professional training for tobacco cessation at primary and secondary healthcare centers and enforcement of ban on tobacco use promotion may accelerate the reduction rate of tobacco use globally. Source: Number of males using tobacco globally on the decline, showing that government-led control efforts work to save lives, protect health, beat tobacco.19 December 2019 News release ,Geneva, Switzerland. 